\title{
Distribution and density of mast cells in camel small intestine and influence of fixation techniques
}

\author{
M.B. Al-Zghoul, ${ }^{1}$ R.K. Al-Rukibat, ${ }^{2}$ M. Alghadi, ${ }^{1}$ T. Caceci, ${ }^{3}$ Z. Bani Ismail ${ }^{4}$ \\ ${ }^{1}$ Department of Basic Medical Veterinary Sciences, ${ }^{2}$ Animal Heath and Pathology, ${ }^{4}$ Veterinary Clinical \\ Sciences, Faculty of Veterinary Medicine, Jordan University of Science and Technology, Irbid, Jordan; \\ ${ }^{3}$ Department of Biomedical Sciences \& Pathobiology, Virginia-Maryland Regional College of Veterinary \\ Medicine, Blacksburg, VA, USA
}

iri

(C2008 European Journal of Histochemistry

This study was carried out to gather species-specific data on mast-cell density and distribution in camel small intestine under different fixation conditions and to elucidate the presence and cross-reactivity of tryptase in the camel small intestine using human specific anti-tryptase antibody. Tissue specimens from the jejunum, duodenum, and ileum were obtained from 9 healthy, 9-12 months old, male camels. Specimens were fixed either with carnoy's fluid or formalinbuffered solution and stained with either methylene blue or immunohistochemically to identify mast cells. The present study demonstrated for the first time, the presence and cross-reactivity of tryptase in the camel small intestine using a specific mouse anti-human tryptase antibody. Mast cells were detected in all histological layers of the camel small intestine (mucosal, submucosal, muscularis externa and serosa). Among all locations examined in the duodenum, ileum and jejunum, no significant difference was observed in mast-cell counts among the lamina propria, muscularis mucosae, muscularis externa and the serosa. The only significant difference observed was the mast-cell count in submucosa region where the highest and lowest mast count was observed in the jejenual and ileal submucosa, respectively. Significant differences regarding the distribution of mast cell as well as the influence of the fixation method could be observed. This underlines the fact that data regarding mast cell heterogeneity from other species, obtained by different fixation methods, are not comparable. This fact has to be taken into account when evaluating mast cell subtypes under pathological conditions.

Key words: camel, distribution, density, fixation, mast cells, small Intestine.

Correspondence: Mohammed Borhan Al-Zghoul, Assistant Professor of Veterinary Anatomy and Histology, Department of Basic Medical Veterinary Sciences, Faculty of Veterinary Medicine, Jordan University of Science and Technology, Irbid 22110, Jordan.

Tel.: +39.962.2.720.1000 Ext. 22010 .

Fax:+39.962.2.7095123.

E-mail: alzghoul@just.edu.jo

Paper accepted on September 9, 2008

European Journal of Histochemistry 2008; vol. 52 issue 4 (October-December):237-242
$\mathrm{M}$ ast cells are heavily granulated wandering cells found in connective tissues in close contact with the external environment (Galli, 1993; Krishnaswamy et al., 2000; Florenzano and Bentivoglio, 2000; Zhi-jia et al., 2005). Mast cell granules contain several biochemical mediators such as heparin, histamine and neutral proteases such as tryptase and chymase with $\beta$-tryptase the most abundant. While its biological function has not been fully clarified, mast cell $\beta$ tryptase plays an important role in inflammation and serves as a marker of mast cell activation (Cairns and Walls, 1996). It is involved in vascular relaxation and contraction (Brown et al., 1995), gastrointestinal smooth muscle activity and intestinal transport (Crowe et al., 1997, Vergnolle, 2000), and coagulation (Huang et al., 1997). Furthermore, serum mast cell $\beta$-tryptase concentration increases in anaphylaxis and in other allergic conditions (Fisher and Baldo, 1994).

Mast cells can be distinguished according to various characteristics. Human, bovine and canine mast cells are distinguished by their content of the mast-cell-specific proteases, chymase and tryptase (Irani et al., 1986, 1989, 1991; Schechter et al., 1990; Weidner and Austen 1993, Kube et al., 1998; Küther et al. 1998). Three mast cell subtypes in humans, bovines and canines can be distinguished: mast cells that contain tryptase (T-MC) only; mast cells that contain both tryptase and chymase (TC-MC); and mast cells that contain only chymase (C-MC). In rats and mice, mucosal and connective tissue mast cells can be distinguished by their different affinities for histological dyes, resulting from the differing proteoglycan content of their storage granules (Enerbäck et al., 1985). A comprehensive search of the literature reveals no data available regarding the normal distribution, density and subtypes of mast cells in camels. The 
present study was carried out to gather speciesspecific data on mast cell density and distribution in camel small intestine under different fixation conditions and to elucidate for the first time the presence and cross-reactivity of tryptase in the camel small intestine using human specific antitryptase antibody.

\section{Materials and Methods}

\section{Animals and specimens}

Fresh camel tissue specimens were obtained from 9 clinically healthy male dromedary camels (9-12 months old) immediately after slaughter. Six fullthickness sections of duodenum, jejunum and ileum were obtained. Specimens were either fixed in 10\% phosphate-buffered formaldehyde overnight or in Carnoy's fluid for 4 hours. After fixation, the tissues were dehydrated in an automatic processor and embedded in paraffin. Serial sections were cut at a thickness of $4 \mu \mathrm{m}$. One section of each tissue sample was stained with hematoxylin and eosin (H\&E) for histopathological evaluation. Lightmicroscopical analysis of $H$ \& $E$ stained sections indicated that all samples used in the study were free of any pathological lesions.

\section{Mast cell detection}

Mast cells were identified by two methods of staining: metachromatic staining using methylene blue stain and by immunohistochemistry.

\section{Metachromatic staining}

Metachromatic staining was performed as described before by Clarke and Maddocks (1965). Briefly, the slides were heated for $10 \mathrm{~min}$ at $60^{\circ} \mathrm{C}$ to melt the paraffin, which was then removed in xylol (2 changes $x 5 \mathrm{~min}$ ). The sections were hydrated through 2 min changes of 100, 90, 70, and $50 \%$ ethanol/water ( $/ / \mathrm{v})$, and then distilled water, and stained with methylene blue (SigmaAldrich, Deisenhofen, Germany) for 5 min. The slides were then rinsed in distilled water. Finally the sections were dehydrated by 1 min changes in 70, 90 , and $100 \%$ ethanol/water (v/v), followed by 1 min in xylol, and cover-slipped using DPX (SigmaAldrich, Deisenhofen, Germany).

\section{Immunohistochemistry}

Immunohistochemical staining was performed using methods described by Irani et al., (1986). Briefly, after deparaffinising the sections in xylol and acetone for $15 \mathrm{~min}$ each, the slides were immersed in TRIS-buffered saline (TBS) $\mathrm{pH} 7.4$ and subsequently in deionised water. endogenous peroxidase was blocked by incubation with $0.6 \%$ $\mathrm{H}_{2} \mathrm{O}_{2}$ in methanol for 30 min at room temperature, followed by washing in Tris-buffered saline with $0.05 \%$ Tween 20 , at pH 7.4 (TTBS). The slides were then incubated with mouse antibodies to human skin tryptase (Promega, Madison, WI, USA) $(1.5 \mu \mathrm{g} / \mathrm{mL})$ for $1 \mathrm{hr}$ at room temperature in a humidity chamber. The slides were then washed with TTBS and peroxidase-conjugated goat antimouse IgG (Jackson Immunoresearch labs, West Baltimore, MD, USA) (1:50 dilution) was added. The slides were re-incubated for $1 \mathrm{hr}$ at room temperature in the humidity chamber. The slides were washed again using TTBS. Diaminobenzidine (DAB) tetrahydrochloride (Sigma-Aldrich, Deisenhofen, Germany) solution containing $0.01 \%$ hydrogen peroxide was used for color development. After a final wash in distilled water, the slides were mounted in a $90 \%$ glycerol solution. Positively stained cells developed a reddish-brown color. Human skin sections were used as positive controls. Negative controls for each tissue specimen were produced by omitting the primary antibody.

\section{Mast cell count}

All tissue sections were examined using light microscopy (Motic Inc., China) by the principal researcher. Positive cells after each staining were counted at a x1000 magnification (oil-immersion) in 10 fields/section and classified according to their microscopical location within epithelia, mucosa, lamina propria (LP), muscularis muscosas ( M M), submucosa ( $S M)$, muscularis externa $(\mathrm{ME})$ and serosa (S). All mast cell profiles in the whole section were counted. Four sections from each sample were counted. Results were expressed as cell $/ \mathrm{mm}^{2}$.

The non-parametric Kruskal-Wallis test followed by the Dunn's multiple comparison test to compare groups were carried out between the mast cell numbers obtained by immunostaining and by methylene blue staining following formaldehyde fixation or fixation in Carnoy's fluid. Statistical analyses were performed using Graphpad Prism for windows (Graphpad Software, California, USA). $p$ values are considered significant when $<0.05$. 


\section{Results}

The MCs stained in the small intestinal tissues typically exhibited a round or oval shape, with diameters ranging from 9 to $15 \mu \mathrm{m}$. The nuclei of MCs were frequently lightly stained, with metachromasia evident in the cytoplasm. The most characteristic feature of these cells was the occurrence of granules in the cytoplasm (Figure 1 A and B). Mast cells containing tryptase were also detected in all histological layers of the camel small intestine after immunohistochemical staining (Figure $1 \mathrm{C}$ and $\mathrm{D}$ ).

Regardless of the staining and fixation technique used, the highest mast cell density was observed in the submucosal layer, with significant numbers of cells found in the perivascular regions, whereas the lowest mast cell density was observed in the muscularis externa. In all tissue sections, a higher mast cell number was detected after fixation in Carnoy's fluid with no cells observed within the epithelia.

Among all locations examined in the duodenum, ileum and jejunum, no significant difference was observed in mast-cell counts in the lamina propria, muscularis mucosae, muscularis externa and the serosa (Figure $2 \mathrm{~A}, \mathrm{~B}$ and $\mathrm{C}$ ). The only significant difference in the mast-cell counts was observed in the submucosa region where the highest and lowest mast count was observed in the jejenual and ileal submucosa, respectively.

\section{Discussion}

The present study was carried out to gather species-specific data on mast cell density and distribution in camel small intestine under different fixation conditions and to elucidate for the first time the presence and cross-reactivity of tryptase in the camel small intestine using human specific antitryptase antibody.

A significantly higher number of camel mast cells and tryptase containing mast cells were detected in most tissue locations of the duodenum, jejunum and ileum after fixation in Carnoy's fluid, regardless of the staining technique used. The superiority of Carnoy's fixation for the detection of mast cells in rodents, human and the dog has been described by others (Becker et al., 1985; Befus et al., 1985; Enerbäck, 1966). The staining methods used to demonstrate mast cells by light microscopy depend on the affinity of cationic dye for the mast cell granule glycosylaminoglycans (GAGs). Optimal fixation will result in precipitation of GAGs leaving polyanionic sites available for binding of dye (Strobel et
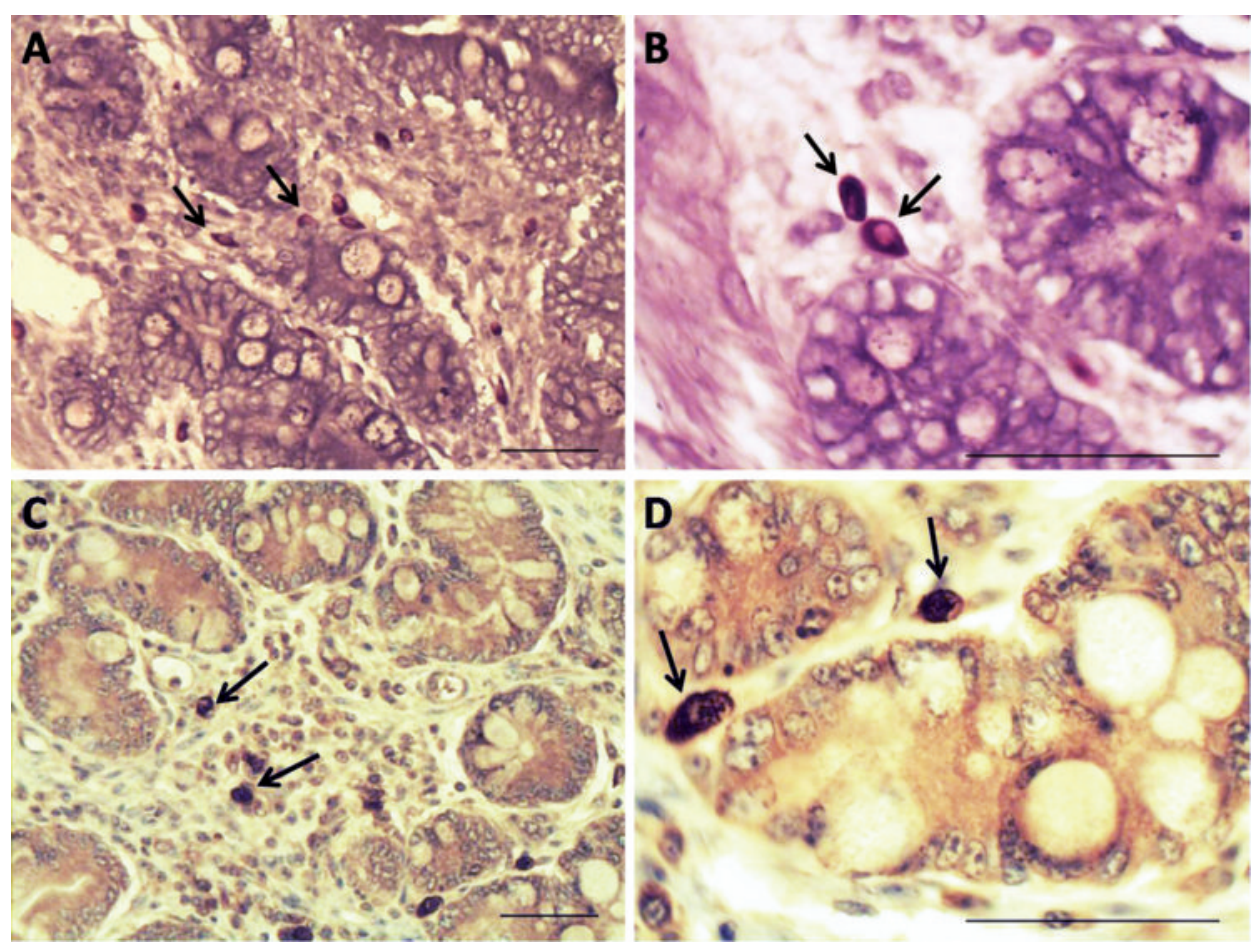

Figure 1. Mast cells distribution in the camel small intestine. Thin sections from duodenum were stained with Methylene blue ( $A$ and $B$ ) and immunostained with mouse antihuman skin mast cell tryptase (C and D). Magnification, X 400 (A, C), and X1000 (oil-immersion) $(B, D)$, arrows in the pictures indicate mast cells. Bar $=\mathbf{5 0} \boldsymbol{\mu m}$. 

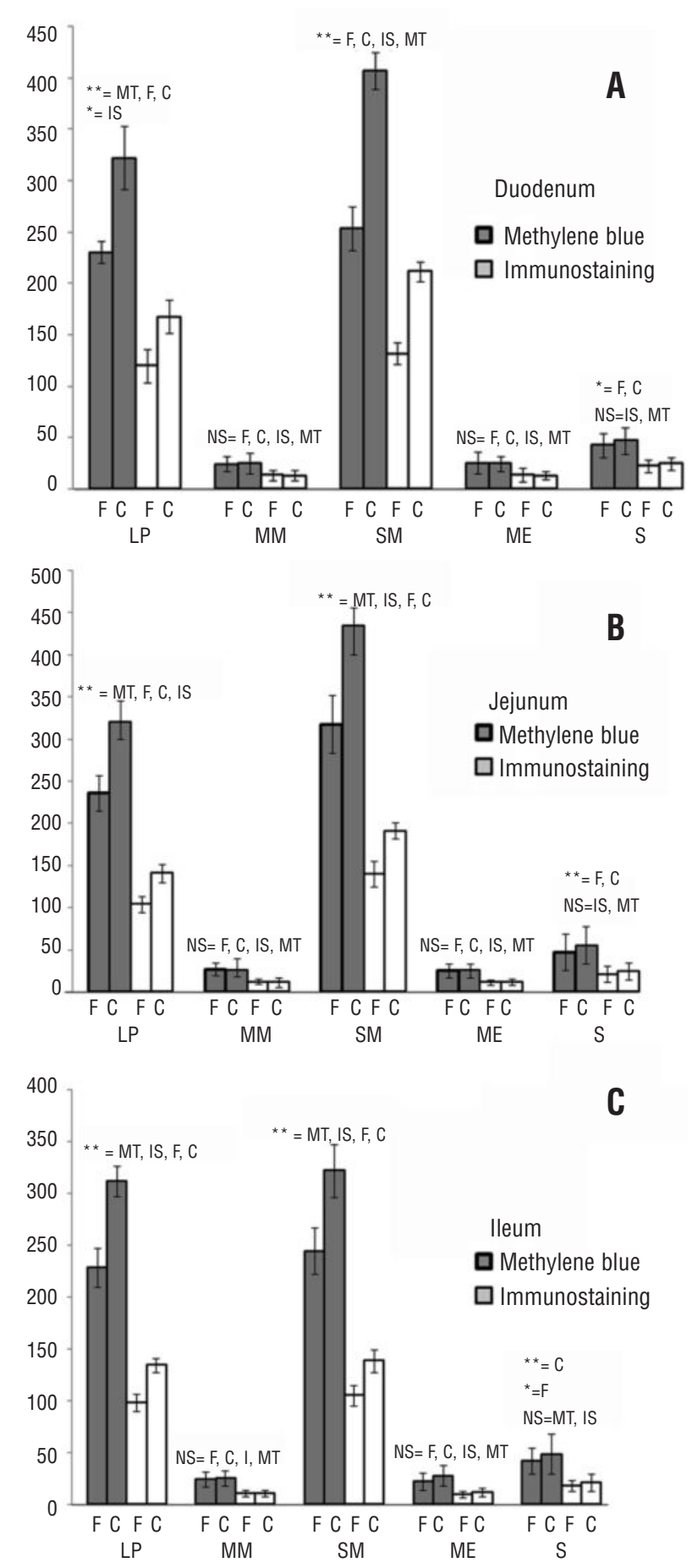

Figure 2. Mast-cell density and distribution in the duodenum, jejunum and ileum as detected by immunostaining (IS) and methylene blue stain (MB) after formalin fixation (F) and fixation using Carnoy's fluid (C). The non-parametric Kruskal-Wallis test followed by the Dunn's multiple comparison test were carried out between the mast cell numbers obtained by IS and by MB stain after formalin fixation (F) or fixation in Carnoy's fluid (C). In addition, the test was carried out between the mast cell numbers obtained with MB staining and fixation in Carnoy's fluid or formalin fixation (MB). Furthermore, the test was carried out after IS and fixation in Carnoy's fluid and formalin fixation (IS). * $p$ value $<0.05,{ }^{*} p$ value $<0.01$, NS: not significant, LP: lamina propria, MM: Musclaris Mucosa, SM: Sub mucosa,

ME: Musclaris Externa and S: Serosa. al., 1981). Failure to demonstrate mast cells in fixed tissues maybe due either to dissolution of nonprecipitated GAG (Enerbäck, 1966) or to blocking of polyanions by cationic proteins (Miller et al., 1972). Carnoys fixatives penetrate tissues rapidly, and precipitate both GAGs and proteins; also the acidity of Carnoy's may facilitate ionic linkages between GAGs and basic cationic (Uvnas et al., 1970). Furthermore; Enerbäck (1985) suggested that aldehyde moieties form a diffusion barrier, blocking the binding of cationic dyes such as methylene blue to the GAGs in the mast cell granules.

We were able to detect camel mast cells containing tryptase in all non-epithelial layers of the camel small intestine. The highest mast cell density was observed in the submucosa, and the lowest mast cell density was observed in the muscularis externa. In this study, we demonstrated for the first time, the presence and cross-reactivity of tryptase in the camel small intestine using a specific mouse antihuman tryptase antibody. This may indicate a tryptase sequence similarity among different animal species. Previously, a polyclonal rabbit antihuman skin tryptase antibody has been used successfully to detect tryptase-containing mast cell in bovine and canine tissue (Kube et al., 1998; Küther et al. 1998).

In our study, we were able to detect camel mast cells containing tryptase in all histological layers of the camel small intestine. In bovine forestomach and duodenum, mast cells of the TC- and the C-subtypes comprise the predominant subtypes in the mucosa, whereas only T-MCs are present in the submucosa (Küther et al. 1998). While, in canine and human, T-MCs are the predominant mast cell subtype in the intestinal mucosa and the TC-MCs occur mainly in the submucosa (Irani et al. 1986, 1989; Weidner and Austen 1993; Kube et al. 1999). Although in this study, the T- MC density and distribution were only reported. Further work will be required to evaluate and estimate of other mast cell subtypes density and distribution.

There were no significant differences observed in mast-cell counts in the lamina propria, muscularis mucosae, muscularis externa and the serosa of the duodenum, jejunum or the ileum in young camels. However, the highest and lowest mast count was observed in the jejenual and ileal submucosa, respectively. This may indicate differences in mucosal immunity involving mast cells in these different regions of the intestine. 
The importance of mast cells in a number of pathological processes is beyond doubt, but because of their poorly defined physiological functions, they have always been a controversial issue (Kamen et al., 1999). Determination of the normal density and distribution of mast cells throughout the camel digestive system may help to reveal their involvement in certain pathological conditions and may improve our understanding of the pathogenesis of the various gastrointestinal disorders.

\section{Acknowledgements}

The authors would like to thank the Deanship of Research at the Jordan University of Science and Technology for sponsoring this project.

\section{References}

Becker A, Chung K, McDonald D, Lazarus S, Frick 0, Gold W. Mast cell heterogeneity in dog skin. Anat Rec 1985;213:477-80.

Befus A, Goodacre R, Dyck N, Bienenstock J. Mast cell heterogeneity in man. I. Histologic studies of the intestine. Int Arch Allergy Immunol 1985;76:232-36.

Brown J, Tyler C, Jones C, Ruoss S, Hartman T, Caughey G. Tryptase, the dominant secretory granular protein in human mast cells, is a potent mitogen for cultured dog tracheal smooth muscle cells. Am J Respir Cell Mol Biol 1995;13:227-36.

Cairns J, Walls A. Mast cell tryptase is a mitogen for epithelial cells: stimulation of IL-8 production and intercellular adhesion molecule1 expression. J Immunol 1996;156:275-83.

Clarke W, Maddocks I. Wool fibre sectioning and staining, differentiation of ortho and paracortex. Stain technology 1965;540:339-42.

Crowe S, Perdue M. Gastrointestinal food hypersensitivity: basic mechanisms of pathophysiology. Gastroenterology 1992;103:1075-95.

Enerbäck L. Mast cells in rat gastrointestinal mucosa. I. Effects of fixation. Acta Pathol Microbiol Scand 1966; 66:3:289-302.

Enerbäck L, Kolset S, Kusche M, Hjerpe A, Lindahl U. Glycosaminoglycans in rat mucosal mast cells. Biochem J 1985; 227:661-8.

Fisher M, Baldo B. Anaphylaxis during anaesthesia. Current aspects of diagnosis and prevention Eur J Anaesthesiol 1994;4:263-84.

Florenzano F, Bentivoglio M. Degranulation, density, and distribution of mast cells in the rat thalamus: a light and electron microscopic study in basal conditions and after intracerebroventricular administration of nerve growth factor. J Comp Neurol 2000; 424:4:651-69.

Galli S. New concepts about the mast cell. N Engl J Med 1993;328:
257-65.

Huang $C$, Wong G, Ghildyal N. The tryptase, mouse mast cell protease 7, exhibits anticoagulant activity in vivo and in vitro due to its ability to degrade fibrinogen in the presence of the diverse array of protease inhibitors in plasma. J Biol Chem 1997;272:31885-93.

Irani A, Schechter N, Craig S, DeBlois G, Schwartz L. Two types of human mast cells that have distinct neutral protease compositions. Proc Natl Acad Sci USA 1986;83:4464-8.

Irani A, Bradford T, Kepley C, Schechter N, Schwartz L. Detection of MCT and MCTC types of human mast cells by immunohistochemistry using new monoclonal anti-tryptase and anti-chymase antibodies. J Histochem Cytochem 1989; 37:1509-15.

Irani A, Goldstein S, Wintroub B, Bradford T, Schwartz L. Human mast cell carboxypeptidase; selective localization to MCTC cells. J Immunol 1991;147:247-53.

Kamen P, Gordon B. Enzyme Histochemistry of Tryptase in Stomach Mucosal Mast Cells of the Mouse. J Histochem Cytochem 1999; 47:617-22.

Krishnaswamy G, Kelley J, Johnson D, Youngberg G, Stone W, Huang $\mathrm{S}$, Bieber J, Chi D. The human mast cell: functions in physiology and disease. Front Biosci 2001;6:1109-27.

Kube P, Audige K, Kuther K, Welle M. Distribution density and heterogeneity of canine mast cells and influence of fixation techniques. Histochem Cell Biol 1998;110:129-35.

Küther K, Audigé L, Kube P, Welle M. Bovine mast cells: distribution, density, heterogeneity, and influence of fixation techniques. Cell Tissue Res 1998;293:111-9.

Miller $\mathrm{H}$, Walshaw $\mathrm{R}$. Immune reactions in mucous membranes. IV Histochemistry of intestinal mast cells during helminth expulsion in the rat. Am J Pathol 1972;69:195-206.

Schechter N, Irani A, Sprows J, Abernethy J, Wintroub B, Schwartz L. Identification of a cathepsin G-like proteinase in the MCTC type of human mast cell. J Immunol 1990;145:2652-61.

Strobel S, Miller $\mathrm{H}$, Ferguson A. Human intestinal mucosal mast cells: evaluation of fixation and staining techniques. J Clin Pathol 1981; 34:851-8.

Uvnas B, Aborg C, Bergendorf A. Storage of histamine in mast cells. Evidence for an ionic binding of histamine to protein carboxyls in the granule heparin-protein complex. Acta Physiol Scand 1970;78: suppl 336:3-26.

Vergnolle N. Proteinase-activated receptors - novel signals for GI pathophysiology. Aliment Pharmacol Ther 2000;14:257-66.

Weidner N, Austen K. Heterogeneity of mast cells at multiple body sites. Fluorescent determination of avidin binding and immunofluorescent determination of chymase, tryptase, and carboxypeptidase content. Pathol Res Pract 1993; 189:156-62.

Zhi-jia Y, Yuval K, Zheng L, and Sherman M. Two types of precursor cells in a multipotential hematopoietic cell line. Proc Natl Acad Sci 2005; 102:51:18461-6. 
M.B. Al-Zghoul et al. 